Published in final edited form as:

Lancet Infect Dis. 2015 June ; 15(6): 634-635. doi:10.1016/S1473-3099(15)00023-7.

\title{
Ethics of HIV research in children
}

\section{Theresa M Rossouw, Johanna Crane, and Lisa M Frenkel}

Departments of Family Medicine and Immunology, University of Pretoria, Pretoria 0001, South Africa (TMR); Interdisciplinary Arts and Sciences, University of Washington Bothell, Bothell, WA, USA (JC); and Departments of Pediatrics, Laboratory Medicine and Global Health, Divisions of Infectious Diseases and Virology, University of Washington, Seattle, WA, USA (LMF)

Theresa M Rossouw: theresa.rossouw@up.ac.za

In their Personal View, Seema Shah and colleagues ${ }^{1}$ addressed ethical issues to be considered in paediatric HIV cure research. The recent rebound of HIV RNA in the socalled Mississippi baby dispelled hopes of a cure, and cautions against use of the term cure. ${ }^{2}$ In a subsequent Correspondence, ${ }^{3}$ the same investigators accepted the limits of our knowledge and the complexity of the scientific questions that remain unanswered, including the optimum time to interrupt antiretroviral therapy (ART) to assess whether therapy initiated in acute infection can eradicate or prevent long-term HIV reservoirs. Shah and colleagues first proposed that therapy be maintained "until ample time has been given for the strategy to work on the basis of existing data", ${ }^{1}$ and then conceded that "how long treatment should be given for the strategy to work is unclear". ${ }^{3}$ We wish to emphasise that, although some data exist on the possible safe interruption of ART, ${ }^{4}$ current data does not inform the optimum time to interrupt infant treatment, which depends on the postulated mechanisms responsible for clearing infection-ie, post-exposure prophylaxis or decay of acutely infected cells.

These intricate questions can probably only be answered in prospective, experimental studies and not in observational research as suggested. Such studies entail intensive, invasive, and specialised monitoring of infants who test positive for HIV infection and necessitate lengthy and complex informed consent documents (ICD), and education of most eligible families will probably be needed. We propose that research be done only in infants at high risk of mother-to-child-transmission (MTCT); that the initial ICD should only consent for maternal or infant treatment during labour and until HIV diagnostic test results are known; and that subsequent ICDs cover research in infants with positive HIV diagnostic tests to elucidate the mechanisms of treatment effecting or failing to effect a cure, and issues pertaining to the interruption of ART. In view of the uncertainties surrounding the interruption of ART, adequate time and repetition should be allowed to ensure satisfactory comprehension.

Finally, we caution that the hope and hyperbole invoked by the term cure does not distract from efforts to improve prevention of MTCT and antenatal services across the world. Since

Correspondence to: Theresa M Rossouw, theresa.rossouw@up.ac.za.

We declare no competing interests. 
only $63 \%$ of the 1.5 million pregnant women infected with HIV in low-income and middleincome countries received effective ART in $2012,{ }^{5}$ we support global efforts to expand and improve prevention-of-MTCT services, coupled with research and interventions directed at the social contexts that allow MTCT to continue in these communities.

\section{Acknowledgments}

This research was supported by the US National Institutes of Health (NIH; grant \#1 R01 A 108366-01) and the Brocher Foundation. JC and TMR are both part of the research team of the HIV Cure group that received the NIH grant and funds a proportion of their time.

\section{References}

1. Shah SK, Persaud D, Wendler DS, et al. Research into a functional cure for HIV in neonates: the need for ethical foresight. Lancet Infect Dis. 2014; 14:893-898. [PubMed: 24906850]

2. National Institute of Allergy and Infectious Diseases, NIH News. [accessed July 21, 2014] 'Mississippi baby' now has detectable HIV, researchers find. 2014 Jul 10. http://www.niaid.nih.gov/ news/newsreleases/2014/pages/mississippibabyhiv.aspx.

3. Shah SK, Persaud D, Wendler DS, et al. Research on very early ART in neonates at risk of HIV infection. Lancet Infect Dis. 2014; 14:797. [PubMed: 25164194]

4. Violari A, Cotton MF, Gibb DM, et al. Early antiretroviral therapy and mortality among HIVinfected infants. N Engl J Med. 2008; 359:2233-2244. [PubMed: 19020325]

5. WHO. [accessed July 21, 2014] Global update on HIV treatment 2013: results, impact and opportunities. 2013 Jun. http://www.who.int/hiv/data/ global_treatment_report_presentation_2013.pdf. 